\section{Hawking on film: first-rate account of a first-rate mind}

Los Angeles. This month, moviegoers across the United States will notice an unfamiliar face among posters featuring the likes of Madonna, Meryl Streep, Clint Eastwood and Marlon Brando. It is British cosmologist Stephen Hawking, starring from his wheelchair in an adaptation of his best-selling book, A Brief History of Time. Director Errol Morris has overcome the obstacles posed by his subject and the topic to present a compelling story of both the man and his science.

Stricken for the past 25 years with Lou Gehrig's disease, Hawking has lost the ability to speak or move and requires round-theclock nursing care. Yet his disability has not stopped him from holding the Lucasian chair at Cambridge University, and the movie suggests a IMAGE parallel between UNAVAILABLE his life and his FOR work. As with a collapsing black COPYIGHT hole, Hawking REASONS has been imploding upon a personal core that centres on his mind. Yet just as a black hole signals its existence

\section{Stephen Hawking} by emitting radiation, Hawking continues
to produce papers and work of high quality. Hawking is the central character of the film, although his mother and others tell parts of his story. We see him grappling with questions of black-hole physics and cosmology, subjects that Morris presents with astonishing integrity and respect for the intelligence of his audience. Virtual particles and event horizons are part of the supporting cast, as are John Wheeler, Kip Thorne, Roger Penrose, Dennis Sciama and Don Page. The narration demands one's full attention; it contains such lines as "A black hole has an entropy; therefore, it has a temperature".

Hawking's disabilities are shown without mawkishness; rather than a poster child seeking pity, he is depicted as a strongwilled man quoting Samuel Johnson's famous line that knowing one is about to be hanged "concentrates the mind wonderfully". At the same time, Morris avoids a portrayal that, as some have already done, invites comparisons to Einstein. Hawking is a scientist of the first rank, Morris makes clear, but not a demigod.

Morris, who received critical and popular acclaim for The Thin Blue Line, a documentary that led to the release of a man falsely convicted of murder, began work on this movie in 1989 at the request of Gordon Freedman of the Los Angeles-based Anglia Television. Morris, who has studied the history of science and attended lectures given by Wheeler at Princeton, found the offer attractive. Indeed, Harvard physicist Sidney Coleman, who served as science adviser for the film, says that he was impressed by Morris' grasp of basic quantum mechanics.

The film was shot in London in 1990 and edited in 1991 before making its US cinematic debut last month in Los Angeles. It cost $\$ 3$ million, a fraction of the usual Hollywood budget. It was shown last spring on British television.

Although the film succeeds in bringing complex scientific concepts to a general audience, it is not without its flaws. For instance, it would have been useful to hear Hawking state clearly that the fundamental problem in cosmology is to reconcile the prediction of general relativity that the universe began from a pointlike mathematical singularity with the impossibility (according to quantum mechanics) of such a singularity. Morris has tried, without much success, to explain some of the ideas Hawking has used to avoid the singularity, but he might have done better to present competing theories from such people as Alan Guth of the Massachusetts Institute of Technology.

However, the very fact that one can raise such points shows how different this film is from the usual fare. One should not criticise a Western shoot-'em-up for not meeting the standards set by Civil War historian Bruce Catton. Likewise, A Brief History of Time upholds the standards set by Hawking himself, which should be high enough to satisfy even the most discriminating viewer.

T. A. Heppenheimer

\section{Dinosaur books get seal of approval from new society}

The best dinosaur books will receive a seal of scientific accuracy from The Dinosaur Society, a Massachusetts-based group of scientists and enthusiasts formed to improve the public's understanding of dinosaurs. The society has identified more than 80 books deemed accurate by a scientific review panel,

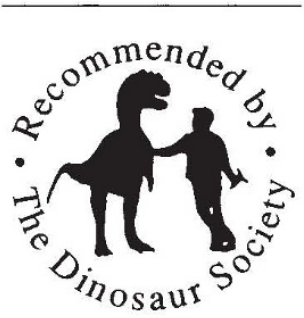
and a handful of titles that it recommends with reservation because of relatively minor errors.

The society declined to release a list of the dinosaur books that flunked the test, although it did single out The Book of Dinosaurs and Other Prehistoric Animals for giving inaccurate time and place information (locating Thecodontosaurus in Australia, a continent where it has never been found, for example), and misstating dinosaur sizes and weights. On the other hand, it gave top honours for accuracy and educational value to The Illustrated Encyclopedia of Dinosaurs, a book by David Norman, a Cambridge University palaeontologist.

The society was founded last year by dinosaur researchers and enthusiasts to increase the $\$ 1$ million now spent worldwide on dinosaur research each year. The society would like some of the money to come from companies selling dinosaur-related products to the public. The group also hopes to raise $\$ 1$ million a year for research through individual and corporate membership, donations, project sponsorships and product endorsements.

Christopher Anderson

The Dinosaur Society can be reached at PO Box 2098 New Bedford, MA 02741, or by telephone, 1-508-999 1168, and fax, 1-508-997-2469.

\section{Chefs forswear genetically altered food}

Restaurant-goers in the United States will soon see this symbol on the menus and windows of some of their favourite establishments as part of a campaign against

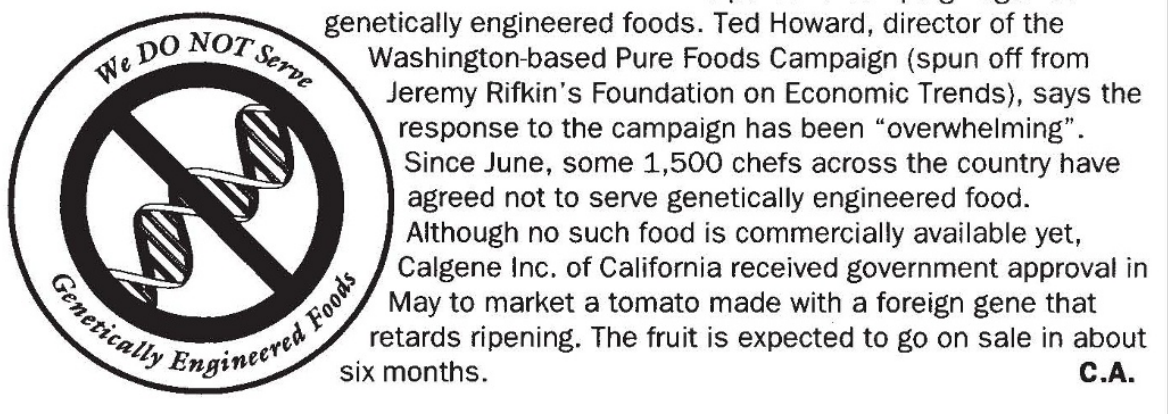

